\title{
Commentary
}

\section{Epigenetic Variants and Biomarkers for Colon Cancer}

\author{
Dongfeng Qu, ${ }^{*}$ Sripathi M. Sureban, ${ }^{* \dagger}$ and \\ Courtney W. Houchen*†‡ \\ From the Department of Medicine,* The University of Oklaboma \\ Health Sciences Center, Oklaboma City; the Department of \\ Veterans Affairs Medical Center, Oklaboma City; and the Peggy \\ and Charles Stephenson Oklaboma Cancer Center, ${ }^{\ddagger}$ Oklaboma \\ City, Oklaboma
}

Colorectal cancer (CRC), the second most common tumor type in the US, is the third leading cause of cancerrelated mortality, accounting for nearly $9 \%$ of all cancerrelated deaths. ${ }^{1}$ Accumulation of mutations in multiple critical genes is believed to cause the transformation of a normal mucosal epithelial cell into a cancer cell. ${ }^{2}$ Mutations in critical genes, such as APC, KRAS, TP53, MMR family genes, CTNNB1, and SMAD4, have been implicated in colon tumorigenesis. In addition to genetic mutations, epigenetic alterations also play important roles in cancer initiation and development. One subtype of CRC, the $\mathrm{CpG}$ island methylator phenotype (CIMP), is characterized by hypermethylation of the $\mathrm{CpG}$ islands in the promoter regions of many tumor suppressor and DNA repair genes, resulting in gene inactivation. ${ }^{3}$ Other epigenetic alterations in CRC include DNA methylation, histone modification, microRNA action, microsatellite instability, and chromosomal instability. ${ }^{4}$

\section{Putative Biomarkers for CRC}

Identifying biomarkers for CRC is essential for cancer prevention, screening, intervention, and surveillance. In general, cancer biomarkers can be divided into three categories: biomarkers as risk factors, biomarkers for early detection, and biomarkers for disease prognosis. ${ }^{5}$ Risk factors, such as genetic inheritance, lifestyle, and diet can only indicate a higher likelihood of cancer occurrence within a certain time in the person with the risk factor compared to the general population. There is no $100 \%$ perfect biomarker for cancer prediction. By contrast, biomarkers for early detection should have near $100 \%$ certainty for cancer occurrence, and the detection should be both sensitive and specific. However, the iden- tification of biomarkers for CRC that can predict prognosis has been elusive. The discovery of such a marker or a set of markers that could be reliably used, not only to predict outcome, but to evaluate response to therapy would fill a major unmet medical need.

Recently, a few putative biomarkers for prognosis of CRC have been reported, such as PROX1, histone deacetylase 1, metastasis-associated protein 1, miR-141, miR-17-92 cluster, and a combined phenotype of SNCG, Hiwi, PRL-3, and ARD1, as well as genes of the extracellular matrix pathway. ${ }^{6-11}$ There is also a very recent report on a 13-gene expression classifier that is specific for stage II CRC. ${ }^{12}$ Several intestinal and colon stem cell markers, such as LGR5, BMI1, and HOPX, are implicated as potential biomarkers for prognosis in CRC as well. ${ }^{13-15}$ These putative biomarkers have been identified in biopsy tissue samples or plasma samples of CRC patients using immunodetection methods or quantitative real-time RTPCR. Considering the heterogeneity of cells in CRC, identifying more precise biomarkers for prognostic use with the potential to increase our understanding of the molecular mechanisms that regulate CRC is clearly needed.

\section{Epigenetic Variant as Prognostic Biomarker}

Isoforms of histone macroH2A, a histone 2A variant, have previously been implicated in lung cancer prognosis. Specifically, the isoform macroH2A1.1, known for its role in cellular senescence, is highly expressed in lung adenocarcinomas enriched with senescent cells but is downregulated in lung carcinomas consisting of mainly proliferating cells. ${ }^{16}$

In this issue of The American Journal of Pathology, Sporn and Jung ${ }^{17}$ report a correlation between macroH2A1.1 down-regulation and CRC prognosis, suggesting that macroH2A1.1 may be a novel CRC prognostic

\section{Accepted for publication April 3, 2012.}

CME Disclosure: C.H. is a founder of COARE Biotechnology, Inc. None of the other authors disclosed any relevant financial relationships.

Address reprint requests to Courtney W. Houchen, M.D, Department of Medicine, Section of Digestive Disease and Nutrition, The University of Oklahoma Health Sciences Center, Oklahoma City, OK 73104. E-mail: Courtney-houchen@ouhsc.edu 
biomarker. The authors demonstrate that macroH2A1.1 mRNA levels are significantly decreased in primary CRC samples compared to those in matched normal colon samples. At the protein level, immunohistochemical analysis indicates that macroH2A1.1 expression levels are significantly lower in tumor cells compared to those in normal colon mucosa. Importantly, down-regulation of macroH2A1.1 correlates with negative outcome for CRC patients. The mRNA expression levels of the other isoform of this variant, macroH2A1.2, are higher in CRC patient samples compared to those in the matched normal colon samples, but there is no correlation with patient outcome. The authors further compared the expression levels of macroH2A1.1 in actively proliferating cells and in more differentiated cells, finding that macroH2A1.1 expression levels are up-regulated during the differentiation of Caco-2 cells. By introducing siRNA specifically targeting macroH2A1.1 into FET cells, a highly differentiated colon cancer cell line, they observed up-regulation of several genes involved in DNA replication, cell survival, and proliferation. These data provide evidence that knockdown of macroH2A1.1 in differentiated cells leads to a phenotype associated with enhanced migration, cell growth, and cell survival. The authors propose that macroH2A1.1 can serve as a prognostic biomarker for CRC outcome, with low expression level of macroH2A1.1 correlating with poor outcome and high expression level of macroH2A1.1 correlating with better recovery.

The integration of genetic mutations and epigenetic alterations have been reported for many CRC biomarkers. ${ }^{11,18}$ Most involve DNA methylation that activates oncogenes and inactivates tumor suppressor genes and DNA repair genes. Histone modification and composition represent additional important factors in epigenetic inheritance, which determines the structure and function of chromatin and regulates genomic DNA accessibility for DNA replication, DNA repair, and RNA transcription. The extra macro domain in macroH2A1 makes it distinct from all core histones, and its association with chromatin remodeling results in transcriptional silencing, such as facultative heterochromatin, centromeric regions, and $X$ chromosome inactivation. ${ }^{19-21}$ Previous studies indicate that macroH2A1.1 is a predictive biomarker for lung cancer recurrence ${ }^{16}$ and that it suppresses melanoma progression. ${ }^{22}$

\section{Future Implications}

Sporn and Jung ${ }^{17}$ identified many genes involved in DNA replication, cell survival, and proliferation to be regulated by macroH2A1.1. Further studies should be undertaken to discover how macroH2A1.1 expression levels are regulated in proliferating cells and more-differentiated cells. It is also imperative to determine whether macroH2A1.1 can be used as a therapeutic target for CRC treatment. Since only $59 \mathrm{CRC}$ samples were used in this report, the sample size should be expanded to further demonstrate the utility of macroH2A1.1 as a prognostic biomarker in clinical practice. Nevertheless, this work not only correlates macroH2A1.1 down-regulation with $\mathrm{CRC}$ patient outcome, but also probes the molecular mechanisms that explain its significance and utility as a CRC prognostic marker.

The recent study by Sporn and Jung ${ }^{17}$ demonstrates that macroH2A1.1 expression levels in CRC correlate significantly with patient outcome. The authors suggest that loss of macroH2A1.1 is probably a general feature of tumorigenesis, is associated with tumor aggressiveness, and can be used as a prognostic marker. This work will significantly advance the field of colon cancer biomarker research for the following reasons: i) CRC is one of the leading cause of cancer related deaths; ii) there are no reliable markers of $\mathrm{CRC}$ with a functional role in cancer progression and metastasis; iii) because macroH2A1.1 is required for maintaining senescence of cancer cells, it may be an ideal therapeutic target for CRC treatment; and iv) macroH2A1.1 plays a major role in proliferation, differentiation, and migration in CRC cells. Therefore, identification of macroH2A1.1 as a novel prognostic biomarker for CRC is a major step toward clinical utilization of functional proteins to assess the risk in patients, resulting in better strategies in designing therapeutic modalities, and ultimately leading to improvement and overall survival of CRC patients.

\section{Acknowledgments}

We thank Nathaniel Weygant for the critical reading of this manuscript.

\section{References}

1. Siegel R, Naishadham D, Jemal A: Cancer statistics, 2012. CA Cancer J Clin 2012, 62:10-29

2. Fearon ER, Vogelstein B: A genetic model for colorectal tumorigenesis. Cell 1990, 61:759-767

3. Toyota M, Ahuja N, Ohe-Toyota M, Herman JG, Baylin SB, Issa JP: $\mathrm{CpG}$ island methylator phenotype in colorectal cancer. Proc Natl Acad Sci U S A 1999, 96:8681-8686

4. Lao VV, Grady WM: Epigenetics and colorectal cancer. Nat Rev Gastroenterol Hepatol 2011, 8:686-700

5. Srivastava S, Verma M, Henson DE: Biomarkers for early detection of colon cancer. Clin Cancer Res 2001, 7:1118-1126

6. Skog M, Bono P, Lundin M, Lundin J, Louhimo J, Linder N, Petrova TV, Andersson LC, Joensuu H, Alitalo K, Haglund CH: Expression and prognostic value of transcription factor PROX1 in colorectal cancer. Br J Cancer 2011, 105:1346-1351

7. Higashijima J, Kurita N, Miyatani T, Yoshikawa K, Morimoto S, Nishioka M, Iwata T, Shimada M: Expression of histone deacetylase 1 and metastasis-associated protein 1 as prognostic factors in colon cancer. Oncol Rep 2011, 26:343-348

8. Cheng $H$, Zhang L, Cogdell DE, Zheng $H$, Schetter AJ, Nykter M, Harris CC, Chen K, Hamilton SR, Zhang W: Circulating plasma MiR141 is a novel biomarker for metastatic colon cancer and predicts poor prognosis. PLoS One 2011, 6:e17745

9. Yu G, Tang JQ, Tian ML, Li H, Wang X, Wu T, Zhu J, Huang SJ, Wan YL: Prognostic values of the miR-17-92 cluster and its paralogs in colon cancer. J Surg Oncol 2011, doi: 10.1002/jso.22138. [Epub ahead of press]

10. Liu C, Qu L, Dong B, Xing X, Ren T, Zeng Y, Jiang B, Meng L, Wu J, Shou C: Combined phenotype of 4 markers improves prognostic value of patients with colon cancer. Am J Med Sci 2012, 343:295-302

11. Yi JM, Dhir M, Van Neste L, Downing SR, Jeschke J, Glockner SC, de Freitas Calmon M, Hooker CM, Funes JM, Boshoff C, Smits KM, van Engeland M, Weijenberg MP, lacobuzio-Donahue CA, Herman JG, Schuebel KE, Baylin SB, Ahuja N: Genomic and epigenomic integra- 
tion identifies a prognostic signature in colon cancer. Clin Cancer Res 2011, 17:1535-1545

12. Agesen TH, Sveen A, Merok MA, Lind GE, Nesbakken A, Skotheim RI, Lothe RA: ColoGuideEx: a robust gene classifier specific for stage II colorectal cancer prognosis. Gut 2012, doi: 10.1136/gutjnl-2011301179. [Epub ahead of press]

13. Takeda K, Kinoshita I, Shimizu Y, Matsuno Y, Shichinohe T, Dosaka-Akita $\mathrm{H}$ : Expression of LGR5, an intestinal stem cell marker, during each stage of colorectal tumorigenesis. Anticancer Res 2011, 31:263-270

14. Li DW, Tang HM, Fan JW, Yan DW, Zhou CZ, Li SX, Wang XL, Peng $\mathrm{ZH}$ : Expression level of Bmi-1 oncoprotein is associated with progression and prognosis in colon cancer. J Cancer Res Clin Oncol 2010, 136:997-1006

15. Harada Y, Kijima K, Shinmura K, Sakata M, Sakuraba K, Yokomizo K, Kitamura Y, Shirahata A, Goto T, Mizukami H, Saito M, Kigawa G, Nemoto H, Hibi K: Methylation of the homeobox gene, HOPX, is frequently detected in poorly differentiated colorectal cancer. Anticancer Res 2011, 31:2889-2892

16. Sporn JC, Kustatscher G, Hothorn T, Collado M, Serrano M, Muley T, Schnabel P, Ladurner AG: Histone macroH2A isoforms predict the risk of lung cancer recurrence. Oncogene 2009, 28:3423-3428

17. Sporn JC, Jung B. Differential regulation and predictive potential of macroH2A1 isoforms in colon cancer. Am J Pathol 2012, 180:25162526
18. Suehiro Y, Wong CW, Chirieac LR, Kondo Y, Shen L, Webb CR, Chan YW, Chan AS, Chan TL, Wu TT, Rashid A, Hamanaka Y, Hinoda Y, Shannon RL, Wang X, Morris J, Issa JP, Yuen ST, Leung SY, Hamilton SR: Epigenetic-genetic interactions in the APC/WNT, RAS/RAF, and p53 pathways in colorectal carcinoma. Clin Cancer Res 2008, 14: 2560-2569

19. Zhang R, Poustovoitov MV, Ye X, Santos HA, Chen W, Daganzo SM, Erzberger JP, Serebriiskii IG, Canutescu AA, Dunbrack RL, Pehrson JR, Berger JM, Kaufman PD, Adams PD: Formation of macroH2Acontaining senescence-associated heterochromatin foci and senescence driven by ASF1a and HIRA. Dev Cell 2005, 8:19-30

20. Rasmussen TP, Mastrangelo MA, Eden A, Pehrson JR, Jaenisch R: Dynamic relocalization of histone macroH2A 1 from centrosomes to inactive $X$ chromosomes during X inactivation. J Cell Biol 2000, 150:1189-1198

21. Costanzi C, Pehrson JR: Histone macroH2A1 is concentrated in the inactive X chromosome of female mammals. Nature 1998, 393:599_ 601

22. Kapoor A, Goldberg MS, Cumberland LK, Ratnakumar K, Segura MF, Emanuel PO, Menendez S, Vardabasso C, Leroy G, Vidal Cl, Polsky D, Osman I, Garcia BA, Hernando E, Bernstein E. The histone variant macroH2A suppresses melanoma progression through regulation of CDK8. Nature 2010, 468:1105-1109 